\title{
THE EFFECT OF HIGH SPINAL ANESTHESIA ON THE RENAL HEMODYNAMICS AND THE EXCRETION OF ELECTROLYTES DURING OSMOTIC DIURESIS IN THE HYDROPENIC NORMAL PREGNANT WOMAN ${ }^{1}$
}

\author{
By N. S. ASSALI, S. A. KAPLAN, ${ }^{2}$ S. J. FOMON, R. A. DOUGLASS, and Y. TADA 3 \\ (From the Departments of Obstetrics and Pediatrics and the Children's Hospital Research \\ Foundation, the University of Cincinnati College of Medicine and the \\ Cincinnati General Hospital, Cincinnati, Ohio)
}

(Submitted for publication May 21, 1951; accepted June 18, 1951)

In previous papers $(1,2)$ it was demonstrated that the normal pregnant woman subjected to autonomic blockade with high spinal anesthesia develops a marked fall in blood pressure leading to a shock-like state.

Since the blood flow to the kidneys constitutes approximately one quarter of the total cardiac output under resting conditions, it seemed that a study of the renal hemodynamics under high spinal anesthesia might afford the opportunity of examining the response of an important part of the vascular bed to this procedure.

Concurrently with the study of renal hemodynamics it was considered of some interest to extend the observations to the excretion of sodium, chloride and potassium. The relationship between renal hemodynamics and electrolyte excretion is at present controversial, and it was thought likely that additional information regarding this relationship might be derived from the present study.

In order to examine the response of the kidneys to this type of autonomic blockade, it was necessary to use a technique which would be applicable to a period of study of short duration. Thus the immediate response to spinal anesthesia could be followed and observations continued until the blood pressure had almost returned to levels preceding the injection of the spinal anesthetic. Previous studies (3-5) employing osmotic diuresis with hypertonic mannitol solution in hydropenia, had shown that this technique was applicable to a short

\footnotetext{
1 This investigation was supported (in part) by research grants from the National Heart Institute of the National Institutes of Health, Public Health Service, and from Parke, Davis and Company, Detroit, Mich.

2 Aided by grant from Eli Lilly and Company.

${ }^{3}$ Fellow in Research, Department of Obstetrics, Cincinnati General Hospital. Present address: National Mishima Hospital, Mishima, Shizuoka-ken, Tokyo, Japan.
}

period of study and that results could be obtained which varied little from individual to individual. Under these conditions sufficiently large urine flows could be obtained in ten minutes to reduce the errors in urine collection and the effects of time lag due to dead space. It should be pointed out, however, that even with this technique such errors cannot be entirely avoided and the results may not accurately reflect short time changes in kidney function. Our own experience (6) with pregnant women before and during high spinal blockade had indicated that the use of water diuresis was not advisable since under these conditions the urine flow is variable and often reaches low volumes insufficient to perform accurate clearances. This was in accord with previous observations in animal and man that water diuresis is inhibited by emotional stress or by afferent stimuli evoked merely by the insertion of a needle into the spinal canal $(7-11)$.

Osmotic diuresis with hypertonic mannitol in hydropenia also had several other advantages to offer. The water-conserving capacity of the kidney of the hydropenic individual could be studied both prior to induction of diuresis and following loading, using the standards of comparison which are defined by the flow-load relationship $(3,5)$. The excretion of sodium and chloride had been shown to vary little throughout this procedure, the concentrations of these two ions in the urine remaining remarkably constant. It would thus be possible to obtain a baseline of renal function which would be consistent from one patient to another. Variations from this pattern brought about by spinal anesthesia would then be readily detectable.

\section{MATERIAL AND METHOD}

The material consisted of five normotensive subjects whose ages varied from 20 to 30 years and who were in 
the last trimester of pregnancy. All had been followed in the prenatal clinic and none had any history of toxemia or renal or hypertensive disease. The patients were admitted to the hospital and kept at bed rest for a few days before the experiment. At 4 p.m. on the day prior to the test, the patients received a dry meal consisting of peanut butter, crackers and raisins. The patients were instructed not to ingest water or food until the next day after the test had ended. At 8 a.m. of the day of the procedure, a spinal anesthesia catheter was introduced into the subarachnoid space, following the technique described elsewhere (1). Thereafter, a multi-eyed Foley catheter was introduced and left in the bladder which was then completely emptied and the urine discarded. A period of 30 minutes was allowed for the patients to relax and for a preliminary urine collection. At the mid-point of this period, a sample of venous blood was taken.

At zero time, which marked the end of the preliminary period, 25\% mannitol solution ${ }^{4}$ in amounts calculated to achieve a plasma level of $20 \mathrm{mOsm} / \mathrm{L}$ was injected. After the priming injection, which was given over a period of 10 to 12 minutes, the plasma level was maintained by continuous infusion at a rate approximately equal to its disappearance rate by means of a constant infusion machine. Para-aminohippurate (PAH) was included in both priming and maintenance solutions in quantities which would enable simultaneous measurement of renal plasma flow. The volume of distribution of mannitol was taken as $20 \%$ of the total body weight and its rate of disappearance calculated as $1.5 \%$ per minute. The corresponding figures for PAH were $40 \%$ and $2.5 \%$ per minute.

An equilibration period of 30 minutes was allowed. At the end of this and of each subsequent period complete urine collections were obtained by aspiration with a

${ }^{4}$ Acknowledgment is made to Sharp and Dohme for their generous supply of mannitol.

TABLE I

$B P, U F, R P F, G F R, F F$, osmotic activity and concentrations of $\mathrm{Na}, \mathrm{Cl}$ and $\mathrm{K}$ during osmotic diuresis with mannitol * All flows are calculated per $1.73 \mathrm{M}^{2}$ per minute

\begin{tabular}{|c|c|c|c|c|c|c|c|c|c|c|c|}
\hline Period & $\begin{array}{c}\text { Concurrent } \\
\text { time } \\
\text { min. }\end{array}$ & $\begin{array}{c}\underset{B P}{M e a n} \\
m m . H g\end{array}$ & $\begin{array}{l}\text { UF } \\
c c .\end{array}$ & $\begin{array}{l}\text { PAH } \\
\text { clearance } \\
c c .\end{array}$ & $\begin{array}{l}\text { Mannitol } \\
\text { clearance } \\
\quad c c .\end{array}$ & FF & $\underset{m E q / L}{\mathrm{Na}}$ & $\underset{m E q / L}{C l}$ & $\underset{m E q / L}{\mathrm{~K}}$ & $\begin{array}{l}\text { Effective } \\
\text { osmotic } \\
\text { activity } \\
m 0 s m / L\end{array}$ & $\begin{array}{l}\text { Load } \\
\mu O s m\end{array}$ \\
\hline \multicolumn{3}{|c|}{ Patient: $W . R$. } & \multicolumn{3}{|c|}{ Weight: $62.4 \mathrm{Kg}$. } & \multicolumn{4}{|c|}{ S. A.: $1.62 M^{2}$} & \multicolumn{2}{|c|}{ Age: 30} \\
\hline Prelim. & -30 to 0 & $108 / 70$ & 0.32 & & & & 59 & 172 & 89 & 1452 & 464 \\
\hline
\end{tabular}

0 to 10 iv. injection of 227 cc. $25 \%$ mannitol; 3.75 cc. $20 \%$ PAH

10 to 101 iv. injection of $25 \%$ mannitol at $3.41 \mathrm{cc} . / \mathrm{min}$.; $20 \% \mathrm{PAH}$ at $0.09 \mathrm{cc} . / \mathrm{min}$.

\begin{tabular}{l|l|l|l|l|l|l|l|l|l|l|l}
\hline 1 & 26 to 39 & $115 / 60$ & 7.88 & 685 & 132 & .19 & 49 & 35.6 & 7 & 629 & 4956 \\
2 & 39 to 50 & $115 / 60$ & 6.79 & 639 & 112 & .18 & 53 & 38.0 & 7 & 553 & 3754 \\
3 & 50 to 62 & $120 / 65$ & 7.04 & 596 & 125 & .21 & 54 & 40.0 & 7 & 569 & 4005 \\
\hline
\end{tabular}

Injection of spinal anesthetic $-8 \mathrm{cc} .0 .2 \%$ procaine

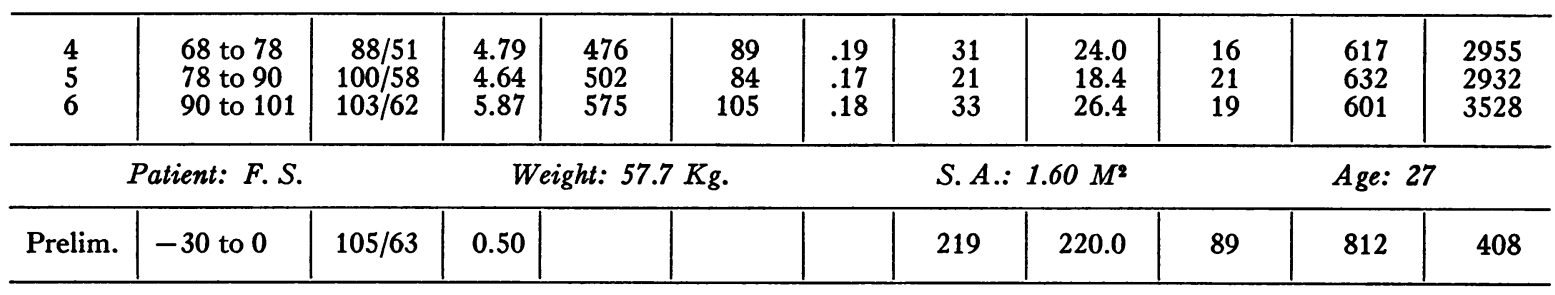

0 to 10 iv. injection of $231 \mathrm{cc} .25 \%$ mannitol; 3.5 cc. $20 \%$ PAH

10 to $100 \mathrm{iv}$. injection of $25 \%$ mannitol at $3.15 \mathrm{cc} . / \mathrm{min}$.; $20 \% \mathrm{PAH}$ at $0.09 \mathrm{cc} . / \mathrm{min}$.

\begin{tabular}{l|l|l|l|l|l|l|l|l|l|l|l}
\hline 1 & 26 to 38 & $116 / 66$ & 6.67 & 867 & 133 & .15 & 62 & 58.0 & 22 & 544 & 3628 \\
2 & 38 to 48 & $116 / 66$ & 6.89 & 804 & 130 & .16 & 62 & 59.6 & 18 & 516 & 3555 \\
3 & 48 to 60 & $116 / 60$ & 6.66 & 767 & 105 & .14 & 61 & 55.2 & 17 & 549 & 3656 \\
\hline
\end{tabular}

Injection of spinal anesthetic $-10 \mathrm{cc} .0 .2 \%$ procaine

\begin{tabular}{l|l|l|l|l|r|r|r|r|r|r|l}
\hline $\mathbf{4}$ & $\mathbf{6 6}$ to 78 & $103 / 52$ & $\mathbf{4 . 7 0}$ & $\mathbf{5 1 7}$ & $\mathbf{7 2}$ & .14 & 40 & 40.0 & 22 & $\mathbf{5 4 6}$ & 2566 \\
$\mathbf{5}$ & $\mathbf{7 8}$ to 88 & $105 / 57$ & $\mathbf{5 . 7 9}$ & $\mathbf{5 6 5}$ & $\mathbf{7 5}$ & .13 & 33 & 33.6 & 24 & $\mathbf{5 2 9}$ & 3063 \\
$\mathbf{6}$ & $\mathbf{8 8}$ to 100 & $\mathbf{1 1 5 / 7 3}$ & $\mathbf{8 . 4 6}$ & $\mathbf{8 6 8}$ & $\mathbf{1 2 0}$ & .14 & 39 & $\mathbf{4 3 . 6}$ & $\mathbf{2 6}$ & $\mathbf{5 3 3}$ & $\mathbf{4 5 0 9}$ \\
\hline
\end{tabular}


TABLE I-Continued

\begin{tabular}{|c|c|c|c|c|c|c|c|c|c|c|c|}
\hline Period & $\begin{array}{c}\text { Concurrent } \\
\text { time } \\
\text { min. }\end{array}$ & $\begin{array}{c}\underset{\mathrm{BP}}{\mathrm{Mean}} \\
m m . \mathrm{Hg}\end{array}$ & $\begin{array}{l}\text { UF } \\
c c .\end{array}$ & $\begin{array}{c}\text { PAH } \\
\text { clearance } \\
c c .\end{array}$ & $\begin{array}{l}\text { Mannitol } \\
\text { clearance } \\
\quad c c .\end{array}$ & FF & $\underset{m E q / L}{N a}$ & $\underset{m E q / L}{\mathrm{Cl}}$ & $\underset{m E q / L}{\mathrm{~K}}$ & $\begin{array}{l}\text { Effective } \\
\text { osmotic } \\
\text { activity } \\
\text { mOsm/L }\end{array}$ & $\begin{array}{l}\text { Load } \\
\text { MOsm }\end{array}$ \\
\hline \multicolumn{3}{|c|}{ Patient: $M . G$. } & \multicolumn{3}{|c|}{ Weight: $62.7 \mathrm{Kg}$. } & \multicolumn{4}{|c|}{ S. A.: $1.66 \mathrm{M}^{2}$} & \multicolumn{2}{|c|}{ Age: 23} \\
\hline Prelim. & -30 to 0 & $105 / 68$ & 0.73 & & & & 112 & 109.6 & 41 & 552 & 403 \\
\hline
\end{tabular}

0 to 10 iv. injection of 227 cc. $25 \%$ mannitol; 3.7 cc. $20 \%$ PAH

10 to $84 \mathrm{iv}$. injection of $25 \%$ mannitol at $3.34 \mathrm{cc} . / \mathrm{min}$.; $20 \% \mathrm{PAH}$ at $0.09 \mathrm{cc}$. $/ \mathrm{min}$.

\begin{tabular}{l|l|r|r|r|r|r|r|r|r|r|r}
\hline 1 & 20 to 31 & $106 / 60$ & 9.36 & 521 & 102 & .20 & 62 & 55.6 & 8 & 457 & 4278 \\
2 & 31 to 41 & $98 / 50$ & 13.31 & 723 & 122 & .17 & 62 & 57.2 & 9 & 440 & 5856 \\
3 & 41 to 52 & $104 / 56$ & 11.90 & 567 & 103 & .18 & 63 & 58.8 & 9 & 446 & 5307 \\
\hline
\end{tabular}

Injection of spinal anesthetic $-8 \mathrm{cc} .1 \%$ procaine

\begin{tabular}{|c|c|c|c|c|c|c|c|c|c|c|c|}
\hline $\begin{array}{l}4 \\
5 \\
6\end{array}$ & $\begin{array}{l}52 \text { to } 62 \\
62 \text { to } 74 \\
74 \text { to } 84\end{array}$ & $\begin{array}{l}67 / 28 \\
53 / 21 \\
80 / 44\end{array}$ & $\begin{array}{l}2.13 \\
3.71 \\
7.53\end{array}$ & $\begin{array}{l}111 \\
320 \\
421\end{array}$ & $\begin{array}{l}22 \\
40 \\
73\end{array}$ & $\begin{array}{l}.20 \\
.13 \\
.17\end{array}$ & $\begin{array}{l}58 \\
19 \\
16\end{array}$ & $\begin{array}{l}54.4 \\
17.6 \\
17.6\end{array}$ & $\begin{array}{l}10 \\
16 \\
20\end{array}$ & $\begin{array}{l}445 \\
440 \\
423\end{array}$ & $\begin{array}{r}948 \\
1632 \\
3185\end{array}$ \\
\hline \multicolumn{3}{|c|}{ Patient: J.S. } & \multicolumn{3}{|c|}{ Weight: $66.6 \mathrm{Kg}$} & \multicolumn{4}{|c|}{ S. A.: $1.66 M^{2}$} & \multicolumn{2}{|c|}{ Age: 20} \\
\hline Prelim. & -30 to 0 & $112 / 66$ & 0.31 & & & & 265 & 222.0 & 35 & 874 & 271 \\
\hline
\end{tabular}

0 to 10 iv. injection of 242 cc. $25 \%$ mannitol; 4.0 cc. $20 \% \mathrm{PAH}$

10 to 102 iv. injection of $25 \%$ mannitol at $3.63 \mathrm{cc} . / \mathrm{min}$.; $20 \% \mathrm{PAH}$ at $0.1 \mathrm{cc} . / \mathrm{min}$.

\begin{tabular}{l|l|l|l|l|l|l|l|l|l|l|r|}
\hline 1 & 27 to 38 & $122 / 70$ & 7.96 & 952 & 132 & .14 & 50 & 37.6 & 10 & 563 & 4481 \\
2 & 38 to 50 & $127 / 74$ & 6.93 & 668 & 100 & .15 & 57 & 42.4 & 8 & 571 & 3957 \\
3 & 50 to 62 & $127 / 74$ & 7.51 & 705 & 118 & .17 & 56 & 44.0 & 8 & 562 & 4221 \\
\hline
\end{tabular}

Injection of spinal anesthetic -6 cc. $1 \%$ procaine

\begin{tabular}{l|l|l|l|l|l|l|l|l|l|l|l}
\hline 4 & 70 to 81 & $87 / 52$ & 3.53 & 419 & 52 & .12 & 37 & 29.6 & 12 & 600 & 2118 \\
5 & 81 to 92 & $113 / 67$ & 4.75 & 523 & 69 & .13 & 18 & 19.2 & 19 & 610 & 2896 \\
6 & 92 to 102 & $100 / 62$ & 3.85 & 412 & 52 & .13 & 16 & 15.6 & 19 & 588 & 2264 \\
\hline
\end{tabular}

Patient: $M . B$.

Weight: $77 \mathrm{Kg}$.

S. A.: $1.76 M^{2}$

Age: 27

\begin{tabular}{|l|l|l|l|l|l|l|l|l|l|l|}
\hline Prelim. & -30 to 0 & $106 / 64$ & 1.31 & & & & 86 & 82.0 & & 279 \\
\hline
\end{tabular}

0 to 15 iv. injection of 280 cc. $25 \%$ mannitol; 4.2 cc. $20 \% \mathrm{PAH}$

15 to $92 \mathrm{iv}$. injection of $25 \%$ mannitol at $4.2 \mathrm{cc}$. $/ \mathrm{min}$.; $20 \% \mathrm{PAH}$ at $0.12 \mathrm{cc} . / \mathrm{min}$.

\begin{tabular}{|c|c|c|c|c|c|c|c|c|c|}
\hline $\begin{array}{l}1 \\
2 \\
3\end{array}$ & $\begin{array}{l}26 \text { to } 37 \\
37 \text { to } 48 \\
48 \text { to } 60\end{array}$ & $\begin{array}{l}120 / 66 \\
114 / 56 \\
116 / 62\end{array}$ & $\begin{array}{r}7.15 \\
10.55 \\
11.63\end{array}$ & $\begin{array}{l}56 \\
84 \\
94\end{array}$ & $\begin{array}{l}47 \\
54 \\
52\end{array}$ & $\begin{array}{l}47.2 \\
52.0 \\
48.0\end{array}$ & $\begin{array}{r}10 \\
9 \\
8\end{array}$ & $\begin{array}{l}273 \\
336 \\
343\end{array}$ & $\begin{array}{l}1952 \\
3545 \\
3989\end{array}$ \\
\hline \multicolumn{10}{|c|}{ Injection of spinal anesthetic -8 cc. $0.2 \%$ procaine } \\
\hline $\begin{array}{l}4 \\
5 \\
6\end{array}$ & $\begin{array}{l}60 \text { to } 70 \\
70 \text { to } 81 \\
81 \text { to } 92\end{array}$ & $\begin{array}{r}49 / 25 \\
101 / 58 \\
106 / 61\end{array}$ & $\begin{array}{l}7.02 \\
3.13 \\
4.56\end{array}$ & $\begin{array}{l}59 \\
44 \\
46\end{array}$ & $\begin{array}{l}50 \\
39 \\
38\end{array}$ & $\begin{array}{l}45.6 \\
30.8 \\
32.8\end{array}$ & $\begin{array}{r}7 \\
10 \\
11\end{array}$ & $\begin{array}{l}356 \\
430 \\
444\end{array}$ & $\begin{array}{l}2499 \\
1346 \\
2025\end{array}$ \\
\hline
\end{tabular}

* $\mathrm{BP}=$ blood pressure; mean is the arithmetic mean of several readings as mentioned in Method. UF = urine flow; $\mathrm{RPF}=$ renal plasma flow; GFR = glomerular filtration rate; FF = filtration fraction.

syringe connected to the catheter and by injecting air into the bladder. Each patient had six collection periods of 10 to 12 minutes' duration. At the midpoint of each period a blood sample was taken from the antecubital vein and transferred to a heparinized vial. Three periods served as pre-spinal controls and three followed induction of the spinal blockade. In three patients, J. S., W. R. and F. S., a period of six to eight minutes was allowed imme- 
diately after the administration of spinal anesthesia, and the urine collected during this period was discarded. In the other two cases collections were started immediately after the injection of procaine. Blood pressure readings (sphygmomanometer) and pulse rate were taken every four to five minutes during the control periods and every half to one minute during the spinal anesthesia.

Three patients received high selective spinal anesthesia to levels of $\mathrm{C}^{4}$ with $0.2 \%$ procaine solution according to the method described elsewhere (1). In the remaining two cases the anesthesia was achieved with $1 \%$ procaine solution and a complete motor paralysis to levels of $\mathrm{T}^{2}$ was obtained.

Urine and plasma specimens were analyzed for their content of mannitol, $\mathrm{PAH}, \mathrm{Na}, \mathrm{Cl}$ and $\mathrm{K}$, using methods previously described (3). Effective osmotic activity of each specimen of urine was determined by measurement of depression of the freezing point.

\section{RESULTS}

In Table I are presented the essential data on five subjects. In it are listed concurrent time, mean readings of systolic and diastolic blood pressure over the period, urine flow, mannitol and $\mathrm{PAH}$ clearances and filtration fraction. The data pertaining to electrolytes refer to the concentrations of $\mathrm{Na}, \mathrm{Cl}$ and $\mathrm{K}$ in the urine. The effective osmotic activity of the urine and excreted load per minute are also given. The amount of loading solute (mannitol), its time of injection, and the rate of administration of the sustaining infusion are presented. The amounts of PAH included for measurement of renal plasma flow are also indicated.

Blood pressure and pulse rate. The response of the blood pressure and pulse rate to the spinal blockade followed the same pattern described in other papers $(1,2)$. It will be seen that the blood pressure dropped markedly during the first few periods following spinal anesthesia and began to return to control levels at the onset of the last period. The pulse rate showed similar variation. The side effects of the procedure were the same as listed in other papers $(1,2)$ except for thirst due to the hydropenic state.

Osmolarity and urine flow. The preliminary urine flows for W. R., F. S., and J. S. were 0.5 cc./min. or less with an effective osmotic activity of more than $800 \mathrm{mOsm} / \mathrm{L}$, indicating that the period of dehydration of 16 hours prior to the beginning of the loading procedure had been ad-

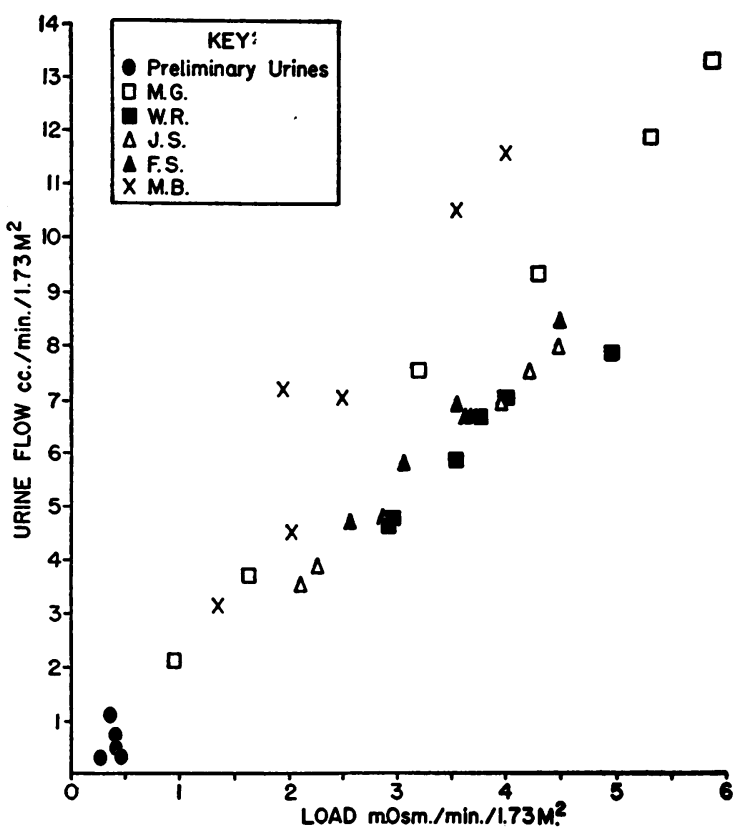

Fig. 1. Urine Flow vs. Excreted LoAd

hered to. From Figure 1 it will be seen that these cases fit well on the flow-load curve as described previously (3) for normal hydropenic individuals and that this relationship between flow and load was not altered by induction of spinal anesthesia.

Two patients were not hydropenic at the onset of the observations. M.G., with a preliminary urine flow of $0.73 \mathrm{cc} . / \mathrm{min}$. and an initial osmolarity of $552 \mathrm{mOsm} / \mathrm{L}$, became hydropenic only during the procedure. The points fell to the left of the curve during the initial post-loading periods, but as dehydration progressed during the induction of forced diuresis the points approached the normal curve. It seems likely that she ingested water during the period preceding the loading procedure. Case M. B. with an initial urine volume of $1.31 \mathrm{cc} . / \mathrm{min}$. and a total osmotic activity of $279 \mathrm{mOsm} / \mathrm{L}$ was certainly not hydropenic at the onset of the procedure nor did she begin to excrete urine with an osmolarity greater than that of plasma until period 2. The restriction of water was thus probably not rigidly enforced in $M$. G. and $\mathrm{M}$. B. and this rendered difficult a consideration of their concentrating abilities. In all cases there was a marked drop in urine flow after induction of spinal anesthesia and a subsequent gradual rise to approximately control levels. 
Renal plasma flow $(R P F) .^{5}$ The effect of spinal blockade on renal plasma flow is consistent for all five subjects. In the cases of W. R., F. S. and J. S., following the autonomic blockade no observations were made on clearance of $\mathrm{PAH}$ until six to eight minutes after injection of procaine intrathecally. In cases M. G. and M. B. these measurements were made immediately following injection of the anesthetic agent. It will be seen that renal plasma flow sustained a marked drop following the introduction of procaine and that this effect gradually wore off, so that 30-40 minutes after injection of the anesthetic agent the PAH clearances were beginning to approach the control levels.

\section{Glomerular filtration rate $(G F R)$ and filtration} fraction $(F F)$. The effect of mannitol clearance closely paralleled that of the PAH clearances. Thus there was no marked change in filtration fraction during the procedure. There was a drop in GFR immediately following the autonomic blockade and a gradual return to control levels within 30-40 minutes.

Renal arterial resistance. ${ }^{6}$ In addition to the observations already made it will be noted from Figures 2 and 3 that the renal arterial resistance both for J. S. and the mean values for the whole series was increased following spinal blockade.

Electrolytes. The excretions of $\mathrm{Na}$ and $\mathrm{Cl}$ paralleled each other. In the post-loading periods the urinary concentration of $\mathrm{Na}$ varied from 47 to $63 \mathrm{mEq} / \mathrm{L}$ and dropped in all cases following autonomic blockade. Unlike the hemodynamic changes, variations in $\mathrm{Na}$ concentration tended to become manifest only after a delay of several minutes after spinal blockade. The $\mathrm{Cl}$ concentrations in the urine likewise fell constantly after spinal

\footnotetext{
5 Because of the small quantities of procaine used in normal pregnant patients, it was considered unlikely that falsely high plasma levels of $\mathrm{PAH}$ due to entrance of procaine in the blood would result and thus interfere with the clearance determinations.

6 The mean renal arterial resistance was calculated according to the formula of Lauson, Bradley and Cournand (12). The formula of Scheinberg and Stead (13) was used for calculation of mean arterial blood pressure. The figure given is actually based on renal plasma flow instead of renal blood flow since hematocrit determinations were not made.
}

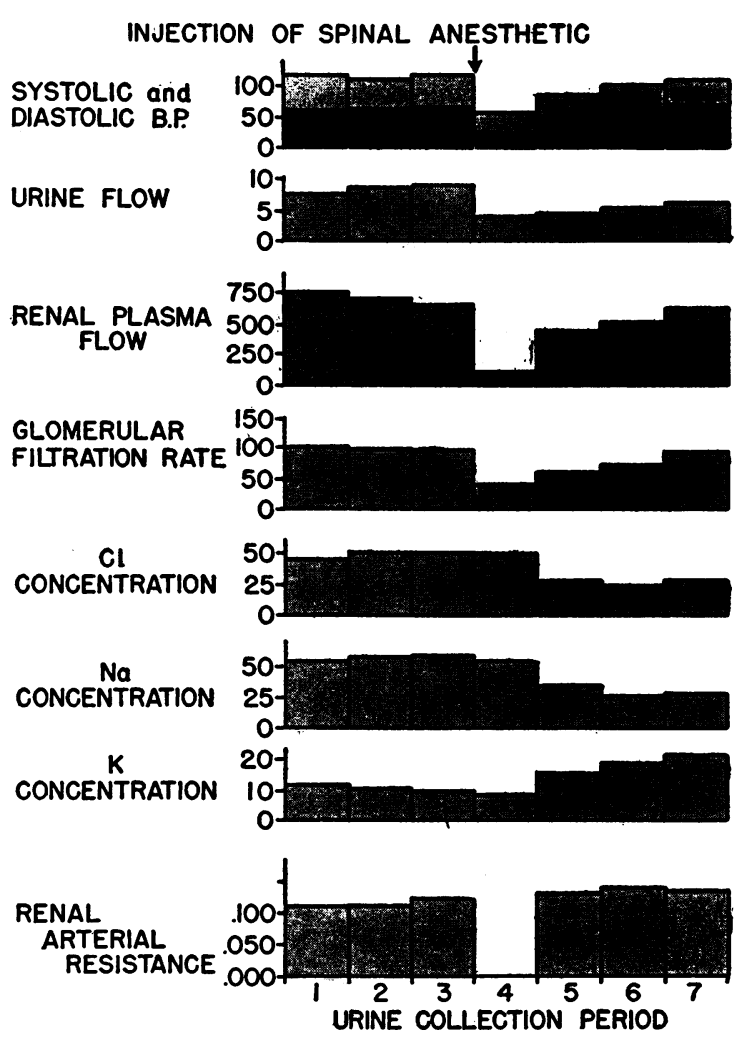

Fig. 2. Mean Values for All Five Cases of Systolic and Diastolic Blood Pressures, Urine Flow, Renal Plasma Flow, Glomerular Filtration Rate, Cl, Na and $K$ Concentrations and Renal Arterial Resistance

The blood pressure readings are in terms of $\mathrm{mm}$. $\mathrm{Hg}$. UF, RPF and GFR are calculated per $1.73 \mathrm{M}^{2} / \mathrm{min}$. Concentrations of $\mathrm{Cl}, \mathrm{Na}$ and $\mathrm{K}$ are in $\mathrm{mEq} / \mathrm{L}$.

anesthesia and the pattern of fall closely resembled that of the $\mathrm{Na}$ values. These values remained low despite the gradual rise of GFR. The concentrations of $\mathrm{K}$ rose after induction of spinal anesthesia in three subjects, but was not significantly altered in two. The minute loss of $\mathrm{K}$ was variable in the different subjects, being decreased by the spinal anesthesia in some and increased in others.

Figure 2 presents the time relationship and the mean values of blood pressure, urine flow, electrolyte concentrations and clearances of mannitol and $\mathrm{PAH}$ in the post-loading periods before and after the spinal blockade. The renal arterial resistance is also indicated after the spinal blockade. Figure 3 presents the findings in subject J. S. who was selected as typical of the series. 


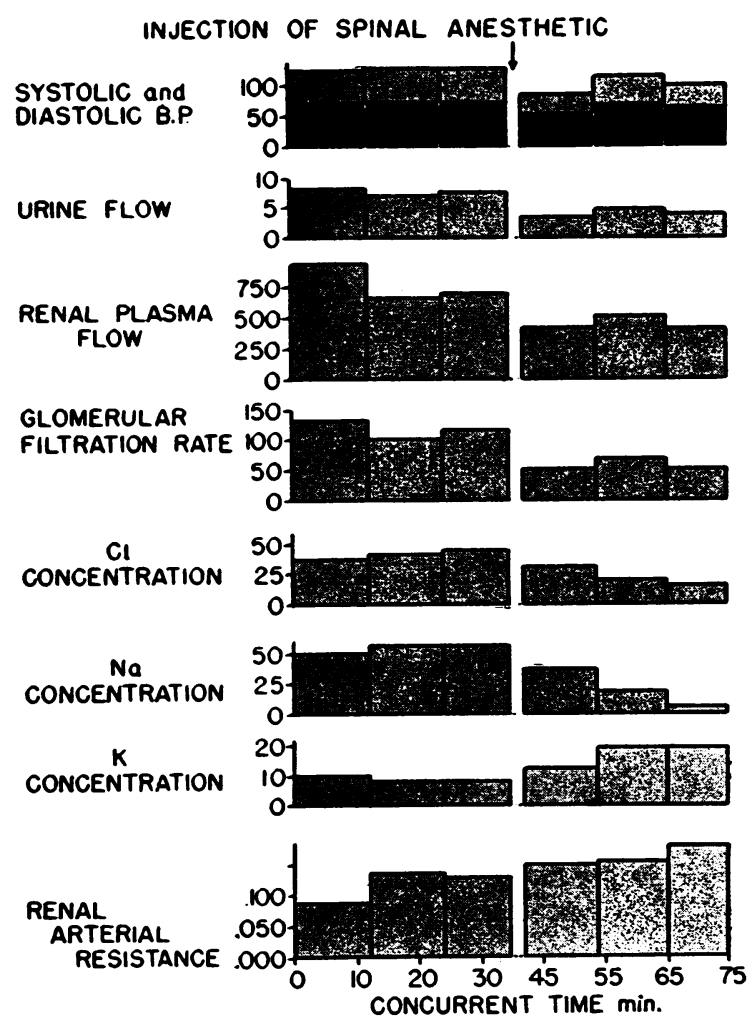

Fig. 3. Case J. S. Systolic and Diastolic Blood Pressures, Urine Flow, Renal Plasma Flow, Glomerular Filtration Rate, Cl, Na and K Concentrations, and Renal Arterial Resistance

The units of measurement are the same as for Fig. 2.

\section{DISCUSSION}

High spinal blockade in the normal pregnant woman affords a unique opportunity of studying the response of renal function to a marked drop in blood pressure since this marked drop is not obtained in the normal non-pregnant individual. Smith and his associates (14) studied the effect of spinal blockade in the normal non-pregnant subject and found no consistent pattern in the changes in renal hemodynamics. Hoobler and coworkers (15) made similar observations using tetraethylammonium chloride (TEAC). In both instances the changes in blood pressure were transient or inconstant. Mokotoff and Ross (16) found no alteration in the renal circulation of patients with congestive heart failure subjected to high spinal anesthesia and in whom the blood pressure was maintained at high levels by the use of ephedrine.
Renal function has been studied in patients with essential hypertension following lumbodorsal sympathectomy, spinal anesthesia and renal denervation (17-23). The results have varied according to the nature of the procedure and experimental conditions.

In patients with toxemia of pregnancy studied under high spinal anesthesia Turner and Houck (24) found a drop in glomerular filtration rate and renal plasma flow in each instance where there was a significant drop in blood pressure. In most cases the renal resistance was increased. They suggested that constriction of the renal arterioles was produced by some humoral agent following spinal anesthesia. Observations on hemorrhagic shock in man and animal $(12,25-27)$, as well as in the post-syncopal state (28), have shown a reduction in renal blood flow and glomerular filtration rate and an increase in renal arterial resistance in most cases where there was a significant drop in the systemic blood pressure accompanied by a drop in the cardiac output.

The analysis of the data presented in this paper leaves little doubt that the reduction in renal plasma flow and glomerular filtration rate produced by high spinal anesthesia in the pregnant woman is caused primarily by the marked drop in blood pressure. Nevertheless, calculation of the renal arterial resistance in the five cases studied showed that the spinal blockade did not produce vasodilatation in the renal blood vessels. Instead there was a tendency toward vasoconstriction as is indicated by a rise in the renal arterial resistance. Since the spinal blockade is effective in blocking autonomic vasoconstrictor fibres $(1,29$, 30 ) it must be inferred that this increase in renal vasoconstriction is caused by a compensatory mechanism which is probably humoral in nature. This hypothesis has been suggested previously (1), following the observation that the blood pressure frequently returns to normal levels despite the maintenance of a high spinal anesthesia. Observations on the action of epinephrine under similar conditions of osmotic diuresis $(31,32)$ have shown that infusion of this agent produces effects similar to those observed here; i.e., a reduction in urine flow, GFR, RPF, and in $\mathrm{Cl}$ and $\mathrm{Na}$ concentrations. It seems possible, therefore, that epinephrine or an epinephrine-like substance may be lib- 
erated into the blood stream in response to the shock-like state observed during spinal anesthesia. Theobald, and Theobald and Verney $(10,11)$ in their experiments on the inhibition of water diuresis by emotional stress concluded that pitressin was responsible for the effects which they observed. In our cases this does not seem likely. The procedures reported here were carried out under conditions of osmotic diuresis in dehydration during which the water-conserving powers of the kidney were being subjected to severe strain and it must be assumed that maximal pitressin-like activity is present prior to induction of the spinal anesthetic. The possibility that these effects are due to liberation of larger quantities of pitressin which then induce active renal vasoconstriction is rendered even less likely since, rather than chloruresis which is an effect of pitressin injection, there was a reduction in chloride excretion.

It has been suggested $(1,2)$ that the fall in blood pressure which follows autonomic blockade with high spinal anesthesia is due either to a pooling of blood in the lower extremities with a concomitant decrease in cardiac output or to a generalized blockade of compensatory vasoconstrictor mechanisms. The data presented in this paper show that active vasoconstriction was proceeding in the kidney during maintenance of the anesthesia and, therefore, would tend to negate the hypothesis that there was paralysis of homeostatic vasoconstrictor mechanisms. The gradual return of blood pressure to normal values despite maintenance of anesthesia is further evidence of increase in the peripheral resistance despite continuation of the autonomic blockade. We are inclined to the belief, therefore, that the drop in blood pressure is due to diminution of venous return owing to pooling of blood in the lower extremities with subsequent reduction in cardiac output and blood pressure.

Concerning the effects of the autonomic blockade per se on renal function little can be said from the present set of experiments. In animals, after unilateral splanchnic nerve section $(31,32)$, osmotic diuresis with mannitol in dehydration is followed by increased sympathetic discharge to the opposite kidney which we believe is part of the general vasoconstrictor response to maintain blood pressure. This results in a reduction of $\mathrm{Na}$ and
$\mathrm{Cl}$ concentrations on the non-denervated side which also exhibits a reduction in urine flow, GFR and RPF as compared with the denervated side. If epinephrine is then infused into the experimental animal both sides are equalized at or near the level of the non-denervated kidney and both kidneys excrete $\mathrm{Na}$ and $\mathrm{Cl}$ in reduced concentrations; urine flow, GFR and RPF are reduced on both sides, the filtration fraction remaining constant. Thus epinephrine discharge masks the effects of section of the sympathetic nervous system. The alterations in kidney function described in this paper closely resemble those observed in these experimental animals and are probably not due to blockade of the renal nerves but to discharge of epinephrine or a related substance.

The discrepancies in the time relationship between GFR and electrolyte excretion are worthy of note. In those cases in which they were measured immediately after induction of the spinal anesthetic the GFR and RPF dropped in the first urine collection period after injection of the anesthetic agent. On the other hand, the concentrations of $\mathrm{Na}$ and $\mathrm{Cl}$ did not drop until several minutes had elapsed after the injection of the spinal anesthetic. The rise in concentration of $\mathrm{K}$, likewise, did not occur until an interval of time elapsed following injection of the spinal anesthetic. Furthermore, despite the return of GFR to control levels by the end of the procedure the concentrations of $\mathrm{Na}$ and $\mathrm{Cl}$ tended to remain at the reduced level. Thus an overall lack of correlation between GFR and electrolyte excretion is evident.

\section{SUMMARY AND CONCLUSIONS}

1. Renal hemodynamics and the excretion of electrolytes were studied during osmotic diuresis in five hydropenic normotensive pregnant subjects before and during high spinal anesthesia.

2. A marked reduction in urine flow, renal plasma flow and glomerular filtration rate was observed during the blood pressure fall following the spinal blockade. The filtration fraction did not change.

3. The excretion of $\mathrm{Na}$ and $\mathrm{Cl}$ was reduced following the blockade. This reduction did not bear any time relationship to the reduction in 
glomerular filtration rate. The effect on $\mathrm{K}$ excretion was variable.

4. The changes in the renal circulation following the spinal blockade were probably produced by two factors :

a) decrease in the renal blood flow due to the blood pressure fall.

b) active compensatory renal vasoconstriction mediated by a humoral agent which tended to counteract the blood pressure fall.

5. It is suggested that epinephrine or an epinephrine-like substance might be the agent responsible for the renal vasoconstriction.

6. The present study supports the hypothesis that the blood pressure fall during spinal anesthesia in the pregnant woman is caused by excessive pooling of blood in the lower extremities and decrease in the cardiac output.

\section{REFERENCES}

1. Assali, N. S., and Prystowsky, H., Studies on autonomic blockade. I. Comparison between the effects of tetraethylammonium chloride (TEAC) and high selective spinal anesthesia on the blood pressure of normal and toxemic pregnancy. J. Clin. Invest., 1950, 29, 1354.

2. Assali, N. S., and Prystowsky, H., Studies on autonomic blockade. II. Observations on the nature of blood pressure fall with high selective spinal anesthesia in pregnant women. J. Clin. Invest., 1950, 29, 1367.

3. Rapoport, S., Brodsky, W. A., West, C. D., and Mackler, B., Urinary flow and excretion of solutes during osmotic diuresis in hydropenic man. Am. J. Physiol., 1949, 156, 433.

4. Rapoport, S., West, C. D., and Brodsky, W. A., Excretion of solutes and osmotic work during osmotic diuresis of hydropenic man. The ideal and the proximal and distal tubular work; the biological maximum of work. Am. J. Physiol., 1949, 157, 363.

5. West, C. D., and Rapoport, S., Urine flow and solute excretion of hydropenic dog under "resting" conditions and during osmotic diuresis. Am. J. Physiol., 1950, 163, 159.

6. Assali, N. S., and Rosenkrantz, J., Inhibition of water diuresis in pregnant women by high spinal anesthesia. Surg., Gynec. \& Obstet., in press.

7. Verney, E. B., Croonian lecture; antidiuretic hormone and factors which determine its release. Proc. Roy. Soc., London, 1947, s.B 135, 25.

8. Verney, E. B., Absorption and excretion of water; antidiuretic hormone. Lancet, 1946, 2, 739.

9. Brod, J., and Sirota, J. H., Effects of emotional disturbance on water diuresis and renal blood flow in the rabbit. Am. J. Physiol., 1949, 157, 31.
10. Theobald, G. W., Repetition of certain experiments on which Molitor and Pick base their water-centre hypothesis, and effect of afferent nerve stimuli on water diuresis. J. Physiol., 1934, 81, 243.

11. Theobald, G. W., and Verney, E. B., Inhibition of water diuresis by afferent nerve stimuli after complete denervation of the kidney. J. Physiol., 1935, 83, 341 .

12. Lauson, H. D., Bradley, S. E., and Cournand, A., Renal circulation in shock. J. Clin. Invest., 1944, 23, 381.

13. Scheinberg, P., and Stead, E. A., Jr., The cerebral blood flow in male subjects as measured by the nitrous oxide technique. Normal values for blood flow, oxygen utilization, glucose utilization, and peripheral resistance, with observations on the effect of tilting and anxiety. J. Clin. Invest., 1949, 28, 1163.

14. Smith, H. W., Rovenstine, E. A., Goldring, W., Chasis, H., and Ranges, H. A., The effects of spinal anesthesia on the circulation in normal, unoperated man with reference to autonomy of arterioles, and especially those of the renal circulation. J. Clin. Invest., 1939, 18, 319.

15. Hoobler, S. W., Moe, G. K., Rennick, B. R., Neligh, R. B., and Lyons, R. H., Effect of autonomic blockade with tetra-ethylammonium on renal circulation in dogs and in normal and hypertensive patients. Univ. Hosp. Bull., Ann Arbor, 1947, $13,9$.

16. Mokotoff, R., and Ross, G., Effect of spinal anesthesia on renal ischemia in congestive heart failure. $J$. Clin. Invest., 1948, 27, 335.

17. Talbott, J. H., Castleman, B., Smithwick, R. H., Melville, R. S., and Pecora, L. J., Renal biopsy studies correlated with renal clearance observations in hypertensive patients treated by radical sympathectomy. J. Clin. Invest., 1943, $22,387$.

18. Rhoads, C. P., Van Slyke, D. D., Hiller, A., and Alving, A. S., Effects of novocainization and total section of the nerves of the renal pedicle on renal blood flow and function. Am. J. Physiol., 1934, 110, 392.

19. Goldring, W., and Chasis, H., Hypertension and Hypertensive Disease. Commonwealth Fund, New York, 1944.

20. Page, I. H., The effect on renal efficiency of lowering arterial blood pressure in cases of essential hypertension and nephritis. J. Clin. Invest., 1934, 13, 909.

21. Page, I. H., and Heuer, G. J., Surgical treatment of essential hypertension. J. Clin. Invest., 1935, 14, 22.

22. Freyberg, R. H., and Peet, M. M., The effect on the kidney of bilateral splanchnicectomy in patients with hypertension. J. Clin. Invest., 1937, 16, 49.

23. Gregory, R., Lindley, E. L., and Levine, H., Studies on hypertension; effect on renal function of decreasing blood pressure of patients with hypertension. Texas Rep. Biol. \& Med., 1943, 1, 59. 
24. Turner, H. B., and Houck, C. R., Renal hemodynamics in the toxemias of pregnancy; alterations of kidney function by regional nerve block. Am. J. Obst. \& Gynec., 1950, 60, 126.

25. Selkurt, E. E., Renal blood flow and renal clearance during hemorrhagic shock. Am. J. Physiol., 1946, 145, 699.

26. Phillips, R. A., Dole, V. P., Hamilton, P. B., Emerson, K., Jr., Archibald, R. M., and Van Slyke, D. D., Effects of acute hemorrhagic and traumatic shock on renal function of dogs. Am. J. Physiol., 1946, 145, 314.

27. Corcoran, A. C., and Page, I. H., Effects of hypotension due to hemorrhage and of blood transfusion on renal function in dogs. J. Exper. Med., 1943, 78, 205.
28. Brun, C., Knudsen, E. O. E., and Raaschow, F., Kidney function and circulatory collapse. Post syncopal oliguria. J. Clin. Invest., 1946, 25, 568.

29. Papper, E. M., Bradley, S. E., and Rovenstine, E. A., Circulatory adjustments during high spinal anesthesia. J.A.M.A., 1943, 121, 27.

30. Sarnoff, S. J., and Arrowood, J. G., Differential spinal block. II. The reaction of sudomotor and vasomotor fibers. J. Clin. Invest., 1947, 26, 203.

31. Kaplan, S. A., Fomon, S. J., and Rapoport, S., Effect of splanchnic nerve division on the urinary excretion of electrolytes during mannitol loading in the hydropenic dog. In preparation.

32. Kaplan, S. A., Fomon, S. J., and Rapoport, S., Effects of epinephrine infusion on the urinary excretion of electrolytes during mannitol loading in the hydropenic dog. In preparation. 